\title{
Cooking Fumes and Relative Diseases
}

\author{
Chunyan WANG \\ Xiangya Nursing School \\ Central South University \\ Changsha, HuNan Province, China \\ e-mail: 767323161@qq.com
}

\author{
Lifang LIU \\ Third Xiangya Hospital \\ Central South University \\ Changsha, HuNan Province, China \\ e-mail:2308321132@qq.com
}

\author{
Guoping HE \\ Xiangya Nursing School \\ Central South University \\ Changsha, HuNan Province, China \\ e-mail: Heguopping@csu.edu.cn
}

\begin{abstract}
Cooking fumes are mixture of various toxic components such as aldehydes, heterocyclic amines (HCAs), polycyclic aromatic hydrocarbons (PAHs), fat aerosols and particulate matters (PM), which are mainly produced during or after cooking. Due to the toxic contents of CFs, CFs might cause lung toxicity, immune toxicity, hereditary toxicity, potential carcinogenicity and so on to organism. There were several studies investigated the toxicity impact of CFs. However, comprehensive review about the production, composition harm to the contacts and reduction methods of CFs is still lacking. In this review, the production, composition and effects on the contacts of cooking fumes were presented. In addition, reduction methods of cooking fumes were also presented. This review would provide references for the avoidance of CFs relative disease and the comprehensive disposal of CFs.
\end{abstract}

Keywords-cooking fumes; toxic contents; toxicity; reduction method

\section{INTRODUCTION}

Cooking fumes (CFs) are mainly produced through complex chemical reaction during or after cooking [1], which were recognized as a source of negative impacts on air quality and human health [2]. Though the components of CFs may be vary depend on the kinds of food, the kinds of cooking oil and the cooking method [3], it contains many kinds of toxic components such as aldehydes, heterocyclic amines (HCAs), polycyclic aromatic hydrocarbons (PAHs), fat aerosols and particulate matters (PM)[1, 4-6]. Many studies have demonstrated that exposed to COFs may increase risk of respiratory tract cancer and many other diseases [2, 7-9]. However, systematic review about the production, composition, effect to the contacts and reduction methods of cooking fume is still lacking.

In this review, the production, composition and effects on the contacts of cooking fumes were reviewed. In addition, reduction methods of cooking fumes were also presented. This review would provide references for the avoidance of CFs relative disease and the comprehensive disposal of CFs.

\section{The Production AND COMPOSITION OF COOKING FUMES}

\section{A. Production of CFS}

Cooking fuels burning, cooking oil volatilization and reaction during heating process, the reaction between food and cooking oil are the main sources for the production of cooking oil fume, which will also affect the composition of CFs $[6,10,11]$. According to the study of To et al. [12] the emissions of extractable organic material depended significantly on the cooking fuel and the cooking process in domestic kitchens and commercial kitchens. Nowadays, natural gas is the mainly cooking fuel in urban while there are still some agricultural stalks and coals using in countryside. Natural gas is mainly composed by $\mathrm{CH} 4$, which will only produced $\mathrm{CO} 2, \mathrm{H} 2 \mathrm{O}$ during burning. Less amount of $\mathrm{CO}$ might also produce during the burning of natural gas under incomplete combustion condition. Relatively, due to the complex components of agricultural stalks and coals, there are much more resultants producing during burning. In addition, electrical heating is also a main cooking method, which is cleaner compared with natural gas, agricultural stalks and coals. Animal and vegetable oils are the most used cooking oil. During the cooking process, oils repeatedly reacted with oxygen from atmosphere at high temperature, which will lead to the oxidation and degradation of cooking oils [13]. Oils would convert to volatile chain scission products, non-volatile oxidized derivatives, and dimeric, polymeric or cyclic substances [14]. Harmful degradation products also may be formed from food at high temperature, which due to the degradation of sugars, pyrolysis of proteins and amino acids and the degradation of fats [15-17].

\section{B. Composition of $\mathrm{CFS}$}

Due to the different cooking oil used, food or cooking method, the composition of CFs may be different. CFs at least contained 200 kinds of compounds, which could be divided into aldehydes, heterocyclic amines (HCAs), polycyclic aromatic hydrocarbons (PAHs), fat aerosols and 
particulate matters (PM) [6, 7, 18-20]. Shields et al. [21] investigated the effects of various appliances such as ovens, broilers and griddles on the production and composition of CFs. The CFs emissions from fatty foods were associated with the cooking appliances; the highest CFs emissions were obtained over open flames. According to Lin et al.[22], the types and quantities of volatile aliphatic aldehydes were depended on the temperature of cooking oil. Francis and Lipinski [23] also demonstrated during barbecue, temperature is important, there were more pollutions producing at higher temperature. Yao et al.[1] examined the effects of deep-frying and frying methods using rapeseed, soybean, peanut, and olive oil on the characteristic of PAHs, results showed deep-frying methods generate more PAHs and benzo[a]pyrene $(\mathrm{B}[\mathrm{a}] \mathrm{P})$, rapeseed oil produced more PAH emission than the other three oil varieties. Ontanón et al. [24] studied volatile compounds released during heating olive and sunflower oil. Results showed the stability of oils during heating process was different, the concentration of alkenes had no significant variation as the temperature changed, and however it was higher in the olive oil. The concentration of alkenes was higher in sunflower oil. According to Gao et al.[25], particulate matters emissions were associated with the heating temperature and had little dependence on the types of vegetable oil used. Differently, Gao [26] found source strengths of particulate matters were highly sensitive to the oil type. Kabir and Kim [5] studied the emission characteristics of various pollutants in relation to 3 food types (including cabbage, clam, and coffee seeds) and 2 cooking methods (between mild and harsh treatments), which found odorant emissions prevailed by roasting coffee seeds followed by brewing coffee, frying cabbage, and grilled clam. The concentrations of the pollutants released from roasting coffee seeds were significantly high relative to other sample types obtained during the cooking periods.

\section{THE EFFECTS OF COOKING Fumes ON THE CONTACTS}

According to World Health Organization (WHO), there are approximately 1.6 million excess deaths annually among human-based combustion activities such as cooking and heating, which account for nearly $3 \%$ of the global burden of diseases [27]. Due to the complex toxic compounds of CFs, CFs might caused lung toxicity, immune toxicity, hereditary toxicity, potential carcinogenicity and so on to organism. Occupational exposure to CFs led to increased oxidative damage [4]. A complex mixture of particulates, metals, volatile organic compounds, polycyclic aromatic hydrocarbons (PAHs), benzene, quinines, and carbonyl compounds will produces during oil heating process, which were related to the formation of reactive oxygen species (ROS) and the induction of cellular events resulting in cell death[27]. Especially polycyclic aromatic hydrocarbons (PAHs) of CFs have carcinogenic properties on mucosal and endothelial lining of upper aero digestive tract [28]. In addition, particularly fine particulate matter (PM2.5) of CFs could penetrate into the lungs readily, which would increase the incidence of respiratory and cardiovascular diseases [29].
Summary of the potential effects of CFs were shown in table I.

TABLE I. COMPONENTS OF CFS AND DAMAGE

\begin{tabular}{|c|c|c|}
\hline Component & Damage & Reference \\
\hline PAHs & $\begin{array}{c}\text { carcinogenic properties } \\
\text { on mucosal and } \\
\text { endothelial lining of } \\
\text { upper aero digestive } \\
\text { tract, oxidative damage, } \\
\text { induction of cellular } \\
\text { events resulting in cell } \\
\text { death }\end{array}$ & [1] [27] [28] [30] \\
\hline Aldehydes & $\begin{array}{l}\text { Mucosa congestion, } \\
\text { respiratory } \\
\text { inflammation, damage } \\
\text { to the macromolecules, } \\
\text { adduct producing } \\
\text { protein carbonyl } \\
\text { compounds, inhibiting } \\
\text { the synthesis of protein } \\
\text { and DNA }\end{array}$ & {$[9][31][32][33]$} \\
\hline $\begin{array}{l}\text { Particulate matter, } \\
\text { especially PM } 2.5\end{array}$ & $\begin{array}{l}\text { penetrate into the lungs, } \\
\text { increase the incidence of } \\
\text { respiratory and lung } \\
\text { cancer }\end{array}$ & [25] [29][34] \\
\hline $\begin{array}{c}\text { Heterocyclic } \\
\text { amines (HCAs) }\end{array}$ & carcinogenic risk & {$[35][36][37][38]$} \\
\hline
\end{tabular}

\section{A. Cooking Fumes Effects on the Gene}

When studying the interaction of XRCC1 and XPD Gene Polymorphisms with Lifestyle and Environmental Factors Regarding Susceptibility to Lung Cancer, Saikia et al. [39] found Interaction of XRCC1Gln/Gln genotype with exposure of cooking oil fumes $(\mathrm{OR}=3.45, \mathrm{CI}=1.39-8.58 ; \mathrm{p}=0.008)$ were significantly associated with increased risk of lung cancer. In addition, Gln/Gln alleles of both XRCC1 and XPD genes showed to amplify the effects of household exposure, smoking and betel quid chewing on lung cancer risk. The hOGG1 Ser326Cys polymorphism might be associated with the risk of lung adenocarcinoma and significant geneenvironment association between cooking oil fumes and hOGG1 326 Cys/Cys genotype in lung adenocarcinoma among female non-smokers was reported by Xue et al. [40].

\section{B. Cooking Fumes Effects on the Cell}

Transforming growth factor- $\beta$ (TGF- $\beta$ ) mainly functioned in regulating cellular functions and has been proven to play an important role in various cancer, the study composed by Ren et al. [41] showed TGF- $\beta 1$ gene C509T polymorphism might be associated with decreased risk of lung adenocarcinoma in Chinese females exposed to cooking oil fumes, but no association was observed TGFBR2 gene 
G875A polymorphism. Che et al. [42] also demonstrated exposure to CFs might lead to mitochondrial and death receptor pathways in AEC II cells, which would finally lead to apoptosis. Exposure to cooking oil fumes might increase the risk of lung adenocarcinoma in Chinese nonsmoking females (adjusted $\mathrm{OR}=1.58,95 \% \mathrm{CI}=1.11-2.25, \mathrm{P}=0.011$ ). However, significant interaction of cooking oil fumes and TP63 polymorphisms was not observed[43]. Cao et al. [44] demonstrated decreased cell viability, increased malondialdehyde (MDA) level, decreased superoxide dismutase (SOD) and glutathione (GSH) activities in a doseand time-dependent manner of CFs, which proved CFs may lead to toxicity in AEC II cells at a very low dose.

\section{Cooking Fumes Effects on the Blood Circulation System}

According to the study carried out by Hecht et al. [45], exposed to CFs has statistically significant effects on the levels of 3-hydroxy propylmercapturic acid and 3-hydroxy1-methylpropylmercapturic acid, but not Sphenylmercapturic acid. The level of creatinine 3hydroxypropylmercapturic acid of women cooking more 7 times a week was $36.8 \%$ higher than that of women who cooking less than once a week. When studying the association between inflammatory markers concentration in blood and exposure to cooking fumes, Svedahl et al. [46] found only small changes in the levels of inflammatory markers in exhaled air and in blood after short-term exposure to moderate concentrations of cooking fumes. The concentration of the d-dimer in blood increased from 0.27 to $0.28 \mathrm{mg} \mathrm{ml}-1$ after exposure to cooking fumes $(\mathrm{P}$-value $=$ 0.004). A trend of an increase in interleukin (IL)-6 in blood, ethane in exhaled air, and IL-1 $\beta$ in EBC after exposure to cooking fumes was also observed.

\section{Cooking Fumes And Lung Cancer}

In the study of $\mathrm{Yu}$ et al. [47], who investigated the relationship between cooking fumes exposures and lung cancer among Chinese nonsmoking women found the risk of lung cancer in Hong Kong nonsmoking women could be increased when cumulative exposed to cooking by means of any form of frying. Similarly, Phukan et al. [48] also reported exposure of cooking oil fumes $(\mathrm{p}<0.003)$, wood as heating source for cooking $(\mathrm{p}=0.004)$, kitchen inside living room $(p=0.001)$, improper ventilated house $(p=0.003)$, roasting of soda in kitchen $(\mathrm{p}=0.001)$, current smokers of tobacco $(\mathrm{p}=0.043)$, intake of smoked fish $(\mathrm{p}=0.006)$, smoked meat $(\mathrm{p}=0.001)$, Soda $(\mathrm{p}<0.001)$ and GSTM1 null genotype $(p=0.003)$ could significantly increase the risk of lung cancer among women in Mizoram. Intake of bamboo shoots $(\mathrm{p}=<0.001)$ and egg $(\mathrm{p}<0.001)$ had significantly protective effect. Kim et al. [11] investigated the association among Home kitchen ventilation, cooking fuels, and lung cancer risk of never smoking women in Shanghai,China. Their research showed poor ventilation increased lung cancer risk (HR: 1.49 ; 95\% CI: $1.15-1.95$ ) for $49 \%$. The use of coal and cooking oil had no significantly impact on lung cancer risk. However, ever coal use with poor ventilation increased the lung cancer risk significantly. According to Metayer et al. [49], exposed to cooking fumes could increase the risk of lung cancer among women. In addition, the risk of lung cancer risks increased along with total number of years cooking (trend, $\mathrm{P}<0.09$ ). Differently, Study carried out by Seow et al. [50] showed, cooking practices did not increase lung cancer risk among nonsmokers but increase the risk of lung cancer among smokers.

\section{REDUCTION OF COOKING FuME}

Due to the high toxic content of CFs and the hazards of CFs to contacts, reasonable disposal of CFs is essential. There are several CFs reduction methods: local ventilation, filtration, catalytic/thermal oxidation, non-thermal plasma technique and biological method [10].

\section{A. Local Ventilation Method}

Among all the reduction method of CFs, local ventilation method is most used. Local ventilation method means using some mechanical means to transfer CFs. Rim et al.[51] investigated the removal efficiency of ultrafine particles produced by coking stoves with kitchen exhaust hoods. Results showed the removal efficiency of ultrafine particles was affected by range hood flow rate and burner position. The removal efficiency of ultrafine particles improved as the increase in the range of hood flow rate.

\section{B. Filtration Method}

Filtration method means using some mediums to absorb the toxic contents in CFs. The removal efficiency of CFs by filtration method is depending on the adsorbing material. However, the adsorbing materials are easily blocked, which will affect the removal efficiency of CFs seriously. In addition, the renewal of adsorbing material also need large amount of capital input, which is not economic.

\section{Catalytic/Thermal Oxidation Method}

Catalytic/thermal oxidation means using catalytic/thermal method to change the toxic contents in CFs to harmless substance. According to Yang et al. [52], who adopted a novel catalyst, based on $\mathrm{MnO} 2 / \mathrm{CuO}$ treating $\mathrm{CFs}$ at a low temperature. Most organics in CFs could be mineralized by this catalyst at the temperature range of $200-300^{\circ} \mathrm{C}$ under the contact time of less than 1 s. $96 \%$ removal efficiency could be achieved if the contact time prolonged to $3.18 \mathrm{~s}$.

\section{Biological Method}

Biological method means using the ability of microorganisms to removal the toxic contents in CFs. In the study of Liao et al. [3], activated sludge was used to decompose pollutants from CFs. Microorganisms showed higher capacity to decompose pollutants; the degradation rate could be $0.15 \mathrm{mg}$ (oil)/mg (biomass) under optimum conditions. Within $28 \mathrm{~h}$, the pollutants concentration of CFs could decrease from 56.9 to $0.78 \mathrm{mg} / \mathrm{L}$.

\section{E. Summary}

Although different reduction methods of CFs have been studied, there are still many limitations during the adoption of these reduction methods. Filtration method need high energy input and equipment needs large area for installation, 
also the pollutions were just transferred not eliminated, which is easily to produce secondary pollution $[10,53]$. The activity of catalyst is easily lost during the application of catalyst in decomposing pollutants from CFs and usually the catalyst is expensive. As to biological method, though the removal efficiency seems high, the removal efficiency is unstable and the reactor of biological method also needs large area for installation. In general, several reduction methods of CFs have been developed; however, there are many limitations during the application of these methods. An efficient reduction method of CFs is till need to develop.

\section{PROSPECT}

CFs is mixture of complex toxic compounds, which might caused lung toxicity, immune toxicity, hereditary toxicity, potential carcinogenicity and so on to organism. Several reduction methods of CFs have been studied. However, there are more or less shortages in these reduction methods. Due to the toxicity of CFs, more research about CFs should be carried out. Meanwhile, comprehensive disposal methods to relieve or eliminate the toxicity of CFs need developing.

\section{ACKNOWLEDGMENTS}

This work was financially supported by the development of the Chinese, Innovative Practice Model of Community Health Nursing (NO.CMB08883)

\section{REFERENCES}

[1] Yao Z. Characteristics of PAHs from deep-frying and frying cooking fumes. Environ. Sci. Pollut. Res. Int. 22(20), 16110-20 (2015).

[2] Wu C. Barbecue Fumes: An Overlooked Source of Health Hazards in Outdoor Settings? Environ. Sci. Technol. 49(17),10607-15(2015).

[3] Liao L.H.T. Liu, and B.L. Zhang, Biodegradability of pollutants from cooking fumes. Bull. Environ. Contam. Toxicol. 82(4), 428-34( 2009).

[4] Wang $\mathbf{J}$ et al. Elevated oxidative damage in kitchen workers in chinese restaurant. J. occup. health 53, 527-533(2011).

[5] Kabir, E. and K.H. Kim, An investigation on hazardous and odorous pollutant emission during cooking activities. J. Hazard. Mater 188(13), 443-54(2011).

[6] Yu, K.-P., et al., Indoor air pollution from gas cooking in five Taiwanese families. Build. Environ. 93, 258-266(2015).

[7] Hung, H.S., et al., Association of cooking oil fumes exposure with lung cancer: involvement of inhibitor of apoptosis proteins in cell survival and proliferation in vitro. Mutat. Res. 628(2), 107-16(2007).

[8] Lee, T. and F. Gany, Cooking oil fumes and lung cancer: a review of the literature in the context of the U.S. population. J. Immigr. Minor. Health 15(3), 646-52 (2013).

[9] Wu, S.C. and G.C. Yen, Effects of cooking oil fumes on the genotoxicity and oxidative stress in human lung carcinoma (A-549) cells. Toxicol. In. Vitro. 18(5), 571-80 (2004).

[10] Park, S.S., M.S. Kang, and J. Hwang, Oil mist collection and oil mistto-gas conversion via dielectric barrier discharge at atmospheric pressure. Sep. Purif. Technol. 151, 324-331(2015).

[11] Kim, C., et al., Home kitchen ventilation, cooking fuels, and lung cancer risk in a prospective cohort of never smoking women in Shanghai, China. Int. J. Cancer136(3), 632-8 (2015).

[12] To, W.M. and L.L. Yeung, Effect of Fuels on Cooking Fume Emissions. Indoor Built Environ. 20(5), 555-563 (2011).
[13] FULLANA, A., A.A. CARBONELL-BARRACHINA, and S. SIDHU, Comparison of Volatile Aldehydes Present in the Cooking.pdf. $J$. Agric. Food Chem. 52, 5207-5214 (2004).

[14] Fullana, A., n.A. Carbonell-Barrachina, and S. Sidhu, Volatile aldehyde emissions from heated cooking oils. J. Sci. Food Agric. 84(15), 2015-2021(2004).

[15] Svendsen, K., Exposure to Cooking Fumes in Restaurant Kitchens in Norway. Ann. Occup. Hyg. 46(4), 395-400 (2002).

[16] Vainiotalo, S. and K. Matveinen, Cooking fumes as a hygienic problem in the food and catering industries. Am. Ind. Hyg. Assoc. J. 54(7), 376-382(1993).

[17] Svedahl, S., et al., Short term exposure to cooking fumes and pulmonary function. J. Occup. Med. Toxicol. 4, 9(2009).

[18] Chen, M.R., P.J. Tsai, and Y.F. Wang, Assessing inhalatory and dermal exposures and their resultant health-risks for workers exposed to polycyclic aromatic hydrocarbons (PAHs) contained in oil mists in a fastener manufacturing industry. Environ. Int. 34(7), 971-5(2008).

[19] Pan, C.H., C.C. Chan, and K.Y. Wu, Effects on Chinese restaurant workers of exposure to cooking oil fumes: a cautionary note on urinary 8-hydroxy-2'-deoxyguanosine. Cancer Epidem. Biomar. 17(12), 3351-7(2008).

[20] Wu, M., W. Che, and Z. Zhang, Enhanced sensitivity to DNA damage induced by cooking oil fumes in human OGG1 deficient cells. Environ. Mol. Mutagen. 49(4), 265-75(2008).

[21] Shields, P., et al., Mutagens from heated Chinese and US cooking oils. J. Nat. Cancer I. 87(11), 836-841(1995).

[22] Lin, J.M. and S.J. Liou, Aliphatic Aldehydes Produced by Heating Chinese Cooking Oils. B. Environ. Contam. Tox. 64(6), 817824(2000).

[23] Francis, G. and R. Lipinski, Control of air pollution from restaurant charbroilers. J. Air Poll. Control Associa. 27(7), 643-647(1977).

[24] Ontanón, I., et al., Application of a new sampling device for determination of volatile compounds released during heating olive and sunflower oil: sensory evaluation of those identified compounds. Eur. Food Res. Technol. 236(6), 1031-1040(2013).

[25] Gao, J., et al., Volume-based size distribution of accumulation and coarse particles (PM0.1-10) from cooking fume during oil heating. Build. Environ. 59, 575-580(2013).

[26] Gao, J., Determination of Size-Dependent Source Emission Rate of Cooking-Generated Aerosol Particles at the Oil-Heating Stage in an Experimental Kitchen. Aerosol Air Qual. Res.13, 488-496(2013).

[27] Liu, Y., et al., Oxidative stress, apoptosis, and cell cycle arrest are induced in primary fetal alveolar type II epithelial cells exposed to fine particulate matter from cooking oil fumes. Environ. Sci. Pollut. Res. Int. 22(13), 9728-41(2015).

[28] Josyula, S., et al., Household air pollution and cancers other than lung: a meta-analysis. Environ. Health.14, 24 (2015).

[29] Mohammed, M.O., et al., Potential Toxicological and Cardiopulmonary Effects of PM 2.5 Exposure and Related Mortality: Findings of Recent Studies Published during 2003-2013. Biomed. Environ. Sci. 29(1), 66-79 (2016).

[30] Sapkota, A., et al., Indoor air pollution from solid fuels and risk of upper aerodigestive tract cancers in Central and Eastern Europe. Environ. Res. 120, 90-95(2013).

[31] Cajelli, E., A. Ferraris, and G. Brambilla, Mutagenicity of 4hydroxynonenal in V79 Chinese hamster cells. Mutation Res. Letters. 190(2), 169-171(1987).

[32] Döhr, O., et al., Effect of Transforming Growth Factor- $\beta 1$ on Expression of Aryl Hydrocarbon Receptor and Genes of AhGene Battery: Clues for Independent Down-Regulation in A549 Cells. Mol. Pharmacol.51(5),703-710(1997).

[33] Foster, K.A., et al., Characterization of the A549 cell line as a type II pulmonary epithelial cell model for drug metabolism. Exp. Cell Res. 243(2), 359-366(1998).

[34] Wan, M.-P., et al., Ultrafine particles, and PM2.5 generated from cooking in homes. Atmos. Environ. 45(34), 6141-6148(2011). 
[35] He, L.-Y., et al., Measurement of emissions of fine particulate organic matter from Chinese cooking. Atmos. Environ. 38(38), 65576564(2004).

[36] Wu, S.-C., G.-C. Yen, and F. Sheu, Mutagenicity and identification of mutagenic compounds of fumes obtained from heating peanut oil. $J$. Food Protect. 64(2), 240-245(2001).

[37] Li, C.-T., et al., Emission of polycyclic aromatic hydrocarbons and their carcinogenic potencies from cooking sources to the urban atmosphere. Environ. Health Persp. 111(4), 483(2003).

[38] Qu, Y., et al., Genotoxicity of heated cooking oil vapors. Mutation Res. Genetic Toxicol. 298(2), 105-111(1992).

[39] Saikia, B.J., et al., Interaction of XRCC1 and XPD Gene Polymorphisms with Lifestyle and Environmental Factors Regarding Susceptibility to Lung Cancer in a High Incidence Population in North East India. Asian Pac. J. Cancer P. 15(5), 1993-1999 (2014)

[40] Xue, X., et al., The joint effect of hOGG1, APE1, and ADPRT polymorphisms and cooking oil fumes on the risk of lung adenocarcinoma in Chinese non-smoking females. PLoS One 8(8), e71157 (2013)

[41] Ren, Y., et al., TGFbeta-1 and TGFBR2 polymorphisms, cooking oil fume exposure and risk of lung adenocarcinoma in Chinese nonsmoking females: a case control study. BMC Med. Genet. 16, 22(2015).

[42] Che, Z., et al., The apoptotic pathways effect of fine particulate from cooking oil fumes in primary fetal alveolar type II epithelial cells. Mutat. Res. Genet. Toxicol. Environ. Mutagen. 761, 35-43(2014).

[43] Yin, Z.-H., et al., TP63 Gene Polymorphisms, Cooking Oil Fume Exposure and Risk of Lung Adenocarcinoma in Chinese Nonsmoking Females. Asian Pac. J. Cancer P. 14(11), 6519-6522(2013).
[44] Cao, J., et al., Toxic effect of cooking oil fumes in primary fetal pulmonary type II-like epithelial cells. Environ. Toxicol. Pharmacol. 36(2), 320-31(2013).

[45] Hecht, S.S., et al., Elevated levels of mercapturic acids of acrolein and crotonaldehyde in the urine of Chinese women in Singapore who regularly cook at home. PLoS One 10(3), e0120023(2015).

[46] Svedahl, S.R., et al., Inflammatory markers in blood and exhaled air after short-term exposure to cooking fumes. Ann. Occup. Hyg. 57(2), 230-9(2013)

[47] Yu, I.T., et al., Dose-response relationship between cooking fumes exposures and lung cancer among Chinese nonsmoking women. Cancer Res. 66(9), 4961-7(2006).

[48] Phukan, R.K., et al., Role of Household Exposure, Dietary Habits and Glutathione S-Transferases M1, T1 Polymorphisms in Susceptibility to Lung Cancer among Women in Mizoram India. Asian Pac. J. Cancer P.15(7), 3253-3260(2014).

[49] Metayer, C., et al., Cooking oil fumes and risk of lung cancer in women in rural Gansu, China. Lung Cancer 35, 112-117(2002).

[50] Seow, A., et al., Fumes from Meat Cooking and Lung Cancer Risk in Chinese Women. Cancer Epidem. Biomar. 9, 1215-1221 (2000).

[51] Rim, D., et al., Reduction of exposure to ultrafine particles by kitchen exhaust hoods: the effects of exhaust flow rates, particle size, and burner position. Sci. Total. Environ. 432, 350-6 (2012).

[52] Yang, J., et al., Treatment of cooking oil fume by low temperature catalysis. Appl. Catalysis B: Environmental 58(1-2), 123-131(2005).

[53] Carter, G.J., Assessing exposure and fume control requirements during arc welding of steel. Welding Cutting 56(6), 364-372(2004). 